\title{
GUANXI VS TALENT ACQUISITION: EVALUATING THE EFFECTS OF GUANXI REFERRALS IN SINO- FOREIGN COLLEGES
}

\author{
DOI: 10.17261/Pressacademia.2019.1155 \\ RJBM- V.6-ISS.4-2019(2)-p.232-242
}

\section{Boidurjo Mukhopadhyay}

University of Sussex, Business and Management, Brighton BN1 9SL, United Kingdom. boidurjo@gmail.com , ORCID:0000-0003-4830-3126

\begin{tabular}{l} 
Date Received: September 27, $2019 \quad$ Date Accepted: December 19, 2019 \\
\hline To cite this document \\
Mukhopadhyay, B., (2019). Guanxi vs Talent Acquisition: Evaluating the Effects of Guanxi Referrals in Sino-Foreign Colleges. Research \\
Journal of Business and Management (RJBM), V.6(4), p.232-242. \\
Permemant link to this document: http://doi.org/10.17261/Pressacademia.2019.1155 \\
Copyright: Published by PressAcademia and limited licenced re-use rights only.
\end{tabular}

\begin{abstract}
Purpose- The objective of the research is to investigate how teaching quality, courses delivered and their learning outcomes, student and staff satisfaction are affected when guanxi and non-guanxi based staffs share the same class cohort and subject levels in the selected colleges for this study. The aim of the research is to show the implications, using a primary data inspected, thematically analysed findings of how these differences in quality control, lack of transparency in hiring and pay packages of guanxi and non-guanxi based recruited staff members affect Chinese and non-Chinese staff expectations and also overall image of foreign Universities who partner with colleges in mainland China. Methodology- The primary data is collected from interviews with a) candidates who have been hired through guanxi referrals, b) candidates who have been recruited in conventional ways with no social-ties benefitting their hiring or position, c) learners from three foreign Universitypartnered colleges in China. Considering the aim, the research strategy was adopted within a qualitative study research design that has applied a thematic analysis.

Findings- The investigation compares faculties who were hired on Guanxi-basis and those who were not, and elucidates on a) A mismatch of staff expertise, courses delivered and learning outcomes, b) Absence of platform to share 'best practices', c) Lack of multi-cultural learning ecosystems in staff rooms, d) Missed learning objectives and teacher-student office hours, and e) Varying financial and moral incentives Conclusion- There are clear challenges coming from guanxi-led hired staff not working closely with non-guanxi counterparts (even when they are teaching on the same course), the lack of access of staff profiles and inability of non-guanxi staff to communicate with guanxi-based staffs. The effects on the wider scale falls on student learning, image of foreign Universities, very high staff attrition rate, quality control measures and falling reputation of these colleges nationally within mainland China.
\end{abstract}

Keywords: Guanxi, China, higher education, academic recruitment, university partnerships, learning outcomes, Sino-Foreign collaboration institutions

JEL Codes: M00, M10, M50

\section{INTRODUCTION}

Guanxi hails from a Confucian culture that rules social behaviours between people. The core value of Confucianism is Ren, meaning 'treat others well' and 'love others' with a wider goal of the society becoming more tolerant, stable and accommodating. Unlike the strong individualism noted in Western countries, every Chinese is a subordinate to his or her own family and is responsible to the family; in China, the family relationship always takes priority over other social relationships tied through contracts (Alston, 1989). Fundamentally, guanxi is derived from two Chinese words, guan (gate or barrier) and $x i$ (connection or link) - so the word suggests 'go through the gate and get a connection'. Chinese Authority's dictionary defines it as 'certain properties of contacts or relations among people'. Simply put, for the lack of an accurate English word, Guanxi can be commonly understood as 'personal relationship' or 'social connection'. This research looks at how guanxi can be the basis of academic recruitment in selected foreign University-partnered colleges in mainland China and the consequent impact on learners and staff satisfaction.

The objective of the research is to investigate how teaching quality, courses delivered and their learning outcomes, student and staff satisfaction are affected when guanxi and non-guanxi based staffs share the same class cohort and subject levels in 
the selected colleges for this study. The aim of the research is to show the implications, using a primary data inspected, thematically analysed findings of how these differences in quality control, lack of transparency in hiring and pay packages of guanxi and non-guanxi based recruited staff members affect Chinese and non-Chinese staff expectations and also overall image of foreign Universities who partner with colleges in mainland China. The structure of this paper initiates by delving into the literature of the traditionally rooted concept of guanxi followed by explaining the methodology and nature of thematic analysis applied for this research, thereafter discusses a mix of broad and specific themes before concluding with research implications.

\section{BACKGROUND}

In the interest of this research as well as how guanxi is better understood in business context, it is pertinent to note that before 90s, the concept was clearly referred to as a 'special' relationship' or 'particular' ties and can be seen differently from other personal relationships (Alston, 1989). Further modern understanding of the concept as China was more accessible after mid 90s, guanxi is a social connection based on mutual interests and benefits, which is usually achieved by exchanging favours and giving social status between guanxi partners (Yang, 1994). Studies have perceived this social concept as an interpersonal utilitarian relationship for reciprocal exchange which is applicable at individual levels (Davies et al., 1995) and equally at the organizational level (Cai, Jun \& Yang, 2010; Gu, Huang, \& Tse, 2008). In contexts where guanxi also helps in shaping the governance and institutional structure, however, it is a means and also social capital in itself which then would lead to advantages in terms of financial performance, marketing access, recruitment sources and favouring of internal candidates (therefore cannot be necessarily termed as 'talent pool') while serving essentially as relationship marketing in Chinese markets (Davies et al., 1995). As an instance however, to clarify further on the individual or group nature of guanxi, it is not always in the form of B2B or C2C, but also can take the shape of B2B2C. Since guanxi is primarily favour, reciprocity in benefitsbased, i.e. when one party expects favours from another party, if one party cannot always deliver from their end, he or she will ask others (in their network) to fulfil a favour through his or her guanxi networks. This social capital, under a code or a set of social norms as understood by Chinese users of the concept, is a utilitarian relationship based on exchanging favours. Typically, guanxi starts from inside the network or family, then ventures (rather slowly) to outside acquaintances so Chinese people choose to believe insiders (people with whom they share guanxi) over outsiders (outside the range of guanxi, per se). Similarities of kinship being a key resource can be noted in other cultures that have also been significantly influenced and structured by Confucianism: Kankei in Japan and Kywankye in Korea, and these correspond to similar meaning of blat in Russia.

Moreover, modern contexts and literature investigating various social, economic and anthropological issues would suggest that China is a relationship society in which people rely more on personal relationships than rational laws (Yang, 1994). Educational institutions, alike financial or other business and service sectors, are guided by regulations, frameworks and guidelines - and are no different in China than in rest of the world. However, the need to find guanxi or to establish a guanxi base contain a set of activities that follow Chinese social norms. In the reality of inefficiency and ineffectiveness of Chinese business infrastructure and related institutions, Chinese people depend more on personal guanxi for commercial protection, legal assurance and risk avoidance specifically. While this may give a sense of security and smoothening of business performance curve (due to information sharing, resource acquirement, cost saving, negotiation), the fall out within guanxi network is a major threat that organisations are aware of in practice. On the other hand, to secure a less risky operational scenario recruitment is also done only within the networks of guanxi who are then entitled to special privileges that would seem discriminatory in organisations that are specification, enforcement and rule based rather than social norm based. Guanxi may bring benefits to individuals as well as the organisations they represent but these benefits are obtained at the expense of other individuals or firms and is thus detrimental to society.

Information management and faster access to emerging policies and market trends along with newer business opportunities are some of the added benefits of having guanxi with government authorities. (Davies, et al, 1995). In many ways thus, guanxi is viewed to be the basis of sustainable competitive advantage (Tsang, 1998; Fock and Shing, 1998); and more conveniently relationship marketing (Ambler,1994; Simmons and Munch, 1996). In China, while guanxi may seemingly be an effective and convenient option for personal networks to play and achieve goals, the Hong Kong Independent Commission Against Corruption in a report holds guanxi accounting for up to $5 \%$ of total costs in doing business in China (ICAC, 1993).

Empirical understanding of guanxi and the use of the same in modern contexts have different realities in application since the element of 'mobility' has changed in societies. Historically, when hukou (living placement and registration of individuals and communities) and danwei (work unit) factors determined job allocation given very few choices available then, this therefore heavily relied on guanxi within limited social circle and reachability in terms of trust based 'who knows who'. This component of localised culture may have barred individuals and communities to reach out beyond their known circles. Clearly with time, reforms and also less political reliance on command economy, the social scenario and communication reachability 
have changed. There may be better and higher options available outside one's guanxi zone, this would have significant impact on any work where such alternatives are available. The sole reliance on one's guanxi network would potentially limit better performance, output and business results in general. In the context of this article, when the higher education sector is investigated the matter becomes more important given the variety of emerging courses in subject areas that are replacing older ones with changing times. In this period, in an Economy that was shut to the world Economy until the 90s, the sole reliance on guanxi to be used as a method of academic job recruitment (mainly internal, therefore) would not improve the sector nor would add to organisational knowledge building over time.

Besides the utilitarian and reciprocity aspects of guanxi, the other components tied with the concept would be transferable and long-term intangible elements of it (Danning \& Kim, 2007). While it has been discussed that guanxi creation and maintenance need time and resources, it also holds high risk. Similar to growth of speed in the quality of guanxi, the fall can be faster as well if one relationship in the chain is negatively affected and consequently affected all connected guanxi in the chain. In terms of the long-term personal intangibility of guanxi, it becomes harder to formalise these relationships in paper when major decisions including financial, recruitment, promotion are based on the same. In regards to the context based on this research, guanxi based recruitment could pose a significant risk to scrutiny when staff members are higher without the right background, qualification and experience in the role that would otherwise require specific criterion from staff applying from 'out of guanxi' range. When such recruitment processes bring in candidates from both guanxi, and non-guanxi referred staffs, the quality control management becomes significantly challenging as the parameters used to judge and appraise employees are not consistent or some may say, even unfair.

\section{Guanxi, Work Performance and Attrition Rate}

Guanxi, worker satisfaction and employee attrition tendency hold a relationship in several forms. Research conducted by Zhai, Lindorff \& Cooper (2012) shows that a supervisor-subordinate Guanxi can have a causal effect on job satisfaction. On the other hand, a negative effect of Guanxi on job satisfaction where a section of employees feels discontented due to the management favouring some individuals, may result in a high turnover intention (Nguyen, Simkin \& Canhoto, 2015). It is important to note that satisfaction and job satisfaction are dependent on job security; insecure employees are both discontented in their employment and may intend to leave for other jobs (Cheung, Wu \& Wong, 2013). Organizational justice that explains the employees' perception of the firm being equitable and fair, can determine the relationship between job security, satisfaction, and turnover intention. Wong, Y., Wong, S., and Wong, Y (2010) argue that Guanxi has a direct relationship with job security from their research in Chinese formal job sector. This research also suggests that an employee would feel more secured at job due to the fact that they were hired on the basis of guanxi and the chances of getting dismissed or missing an opportunity to other (non-guanxi) employees are significantly lower. However, they also suggest that the relationship between the Guanxi and job security is dependent on the performance of the employee; irrespective of a favourable relationship, an underperforming employee may lack job security. The figure below represents the conceptual model that the study will adopt.

Knowledge building exercises get a boost when employees create networks outside their immediate professional relationships, these networks enable access to sensitive information related to jobs and organisations that people work for (Chen et al, 2011). Consequently, professionals become more aware of the treatment and working conditions that organisations are expected to maintain and offer employees, this may be contrary to their personal experiences in firms. Further, employees get dissatisfied with their employees and workplaces when the management is not willing to improve or note the required issues or changes. As things become clearer through communication, employees may get to know how guanxi for example served as the recruitment criterion for some of their colleagues which benefitted them unfairly over others. This dissatisfaction ultimately does affect staff motivation at workplace and subsequently increases willingness to switch over and leave their current workplace. The matter is not always entirely in favour of guanxi referred employees, as there may come a point when employees may get very satisfied in their current roles and would like to experience selfactualisation where the guanxi does not work in favour any longer (Abosag \& Naudé, 2014). However, organisational culture and individual performance and performance relationship circumstances may also lead to increase in turnover intention overtime (Scott et al., 2014). Nevertheless, guanxi connected employees may have higher job satisfaction in general due to the fact that they would usually get the employer support necessary for satisfying group and individual goals in the initial (at the very least) years of employment. Conclusively, Guanxi has an almost similar impact on job satisfaction and the turnover intention. As an exception however, and this is where literature falls short of a scenario of low morale and lack of significant achievement of group goals when the work environment hosts both guanxi based and non-guanxi based staffs working together in the same team and towards common shared goals. 


\section{METHODOLOGY}

The core purpose of this research is to investigate the effects of guanxi-based (or 'favoured') recruitment of academic staff on quality assurance and effective delivering of learning outcomes in sino-foreign joint educational institutes in mainland China. The primary data is collected from a) candidates who have been hired through guanxi referrals, b) candidates who have been recruited in conventional ways with no social-ties benefitting their hiring or position, c) learners from three sinoforeign joint colleges in China. Considering this aim, the research strategy was adopted within a qualitative study research design. This is in line with important recommendations in the literature (Dana \& Dana, 2005, Dana \& Dumez, 2015) pointing out the need for expanding research methodologies beyond quantitative studies with a wider inductive and holistic perspectives.

The chosen qualitative approach for the paper has used a thematic analysis. Thematic analysis is a search for themes that emerge as being important to the description of the phenomenon (Daly et al, 1997). Braun and Clarke (2006) views thematic analysis as a method used for 'identifying, analysing, and reporting patterns (themes) within the data' (2006: 79). Generally, thematic analysis is the most widely used qualitative approach to analysing interviews. The process involves the identification of themes through 'careful reading and re-reading the data' (Rice \& Ezzy, 1999: 258). It is a form of pattern recognition within the data, where emerging themes become the categories for analysis.

The primary data collected from 34 Lecturers grade A and grade B faculties, please note table 1 below for more details. Investigating interviewees at the same position or title (i.e. Lecturer) would facilitate the research with a standardised and focused understanding of how guanxi may play a role in candidate profile and also performance related aspects. The contracts are primarily teaching and service heavy with minimal or no research expectations (i.e. with no workload hours or research support grants provided), based on pre-agreements with candidates, with a total 16 full-time and 18 part-time contracts looked at.

Table 1: Respondent Details

\begin{tabular}{|c|c|c|c|c|c|}
\hline Number of respondents & Male & Female & Chinese & Foreign & Online profile \\
\hline 34 & 13 & 21 & 23 & 11 & 8 (foreigners only) \\
\hline
\end{tabular}

\subsection{Codes and Themes}

A 'good code' is one that captures the qualitative richness of the phenomenon, and the coding process involved recognising an important moment and encoding prior to a process of interpretation (Boyatzis, 1998:1). Encoding the information organises the data to identify and develop themes from them. Boyaztis (1998:1) defined a theme as ' $a$ pattern in the information that at minimum describes and organises the possible observations and at maximum interprets aspects of the phenomenon'. Coding is the process of organising and sorting data since it serves as a way to label, compile and organize data. In linking data collection and interpreting the data, coding becomes the basis for developing the analysis.

Table 2: Modified and Adapted from Crabtree \& Miller (1999)

\begin{tabular}{|c|l|l|}
\hline Stage & Action taken & Description \\
\hline 1 & $\begin{array}{l}\text { Developing a template } \\
\text { of codes }\end{array}$ & $\begin{array}{l}\text { the semi structured interview questionnaire had a set of codes embedded in the } \\
\text { questions that were drawn both from literature as well as the conceptual } \\
\text { framework }\end{array}$ \\
\hline 2 & $\begin{array}{l}\text { Testing the reliability of } \\
\text { codes }\end{array}$ & $\begin{array}{l}\text { Drawing the codes from elements identified from the interviews were further } \\
\text { categorised in themes. Some codes were ignored because of the purpose of this } \\
\text { research. }\end{array}$ \\
\hline 3 & $\begin{array}{l}\text { Summarising data and } \\
\text { identifying initial } \\
\text { themes }\end{array}$ & $\begin{array}{l}\text { Following reviewing interview data, the responses were collated and the raw data } \\
\text { was systematically summarised. Interview transcripts were summarised separately } \\
\text { by outlining the key points made by participants in response to the questions } \\
\text { asked. }\end{array}$ \\
\hline 5 & $\begin{array}{l}\text { Connecting the codes } \\
\text { and identifying themes }\end{array}$ & $\begin{array}{l}\text { the codes identified from both 'a priori' ones and also 'emerging codes' } \\
\text { contributed to a better list of responses that would provide a higher } \\
\text { understanding. Connecting codes is the process of discovering themes and } \\
\text { patterns in the data }\end{array}$ \\
\hline
\end{tabular}


Data analysis followed several stages. First, each interview transcription was scrutinised and themes were generated. Each response provided was examined with respect to the type of staff (Chinese national and non-Chinese national) and the institution they were working for. This helped in creating first order codes. Second order codes were identified and grouped together in what emerged across the interview responses to specific question sets (collected from both primary interviews and questionnaire responses via email) to carry out an analysis systematically. Eisenhardt (1989) viewed that it is important that the data analysis process is based on both 'within' story and 'cross' story analysis. Since most of the themes were generated from collating responses that were pointing towards a common fact or a phenomenon, from a range of interview findings, the analysis shifted from the individual level to collective analyses. This enabled in drawing general conclusion and meaning to a given question if there were common themes generating due to repeat or similar responses.

\section{FINDINGS}

\subsection{A Mismatch of Staff Expertise, Courses Delivered and Learning Outcomes}

'My role is primarily about staff administration and overseeing foreign partner recruitment numbers...in addition, liaising with student parents and teaching assistants for smooth running of classes and heading the management of annual automotiveshow that is hosted on campus... The international office takes care of on-rolling recruitment and staff requirements round the year'

The role of Academic Dean, a Chinese national, for one of the selected sino-foreign colleges includes being the programme director for all undergraduate programmes in business, engineering, media and IGCSE exams, monitoring quality assurance and arranging peer reviews, employee appraisal and staff reviews, liaising with local industries to host job fair and career support for students. The position has been held by the same person for over 15 years with strong connection/guanxi with local government authorities, and three vice presidents along with one exective president above him who owns the college financially. None of the role above, however, associated with title of the role has accessible paperwork as an evidence. In many circumstances, some of these above roles are delegated to early career teaching assistants whose responsibilities are largely undefined but includes foreign teacher support as well as school admin work like managing course portfolios and student accommodation management roles. No job descriptions are listed in their contract nor available in detail when contacted. In addition, these staff members don't have any online profile alike other teaching staff so more information regarding their job suitability monitoring, equally an understanding of their work overload is missing due to lack of clarity of communication and transparency of information.

"The syllabus for IGCSE Mathematics is almost same as it is in Philippines (teacher origin), no teaching license is required to teach IGCSE in this college... The teaching assistant gives us the course portfolio from last year which is enough to get on with. The students have their learning portfolio which they can learn from, in addition to the classes filled with exercises handed down from my predecessor of the course... I do not have to invent any resources."

The criterion for recruiting certain staff members, including non-Chinese, is also not clear and defined in any paperwork. It is difficult to assess aspects such as teaching pedagogy and therefore strict requirements set by higher education frameworks are hard to monitor and evaluate whether they are delivered in the classroom. There is almost no involvement of foreign partner Universities in recruitment decisions in these three colleges studied, and also no contact is made with staff (both new and old) from these partners institutions. Quality assurance rounds and visits have no regional branch staff participation; therefore, no involvement of faculties is taken on board or best practice shared platform is enabled.

\subsection{Absence of a Platform to Share 'Best Practices'}

There is a need for foreign staff to work closely with local staff which becomes all the more important when they are sharing the same students across courses based on specialisation, besides many other student monitoring and development benefits. Data suggests that there is limited or no communication throughout the semester, and the platform where they put their queries forward is via teaching assistants. This may jeopardise the learning setting since students can feel the lack of consistency and connectivity in courses that they have during a semester. The importance of having a common staff room could be emphasised here as also noted by the staffs working in one of the colleges before.

"The readings for listening and other English language courses could better benefit my kids [students] if there is an opportunity to work or meet with their English teachers... This never happens, and the variation noticeable in the standard of reading material in their English classes significantly differs from case study readings that I present for my lessons... Students who score higher grades in their English language assignments are sometimes at a lower rung for my business courses. They can't understand how this is possible... When asked for English reading materials, the teaching assistant was unable to provide it 
and emails/ WeChat were ignored... it would be useful to have a staff meeting or a common staff room where these can be openly discussed perhaps?"

The above quote from a non-Chinese business Lecturer, elucidates the gap in learning and also inability of students to comprehend nature and outcome of their performances due to a) lack of feedback, b) lack of synchronisation between staffs teaching the same student cohort with similar course level learning objectives.

"My teaching assistant for $2^{\text {nd }}$ year Marketing course is a Chinese staff who also teaches a similar strategy course for the third years, however she feels that she doesn't always feel very confident in delivering the ppt coming from the publishers since she doesn't have a Master's degree yet [that I have as a requirement for this post]. It is difficult to build a new assignment, for example, without anybody in the teaching team to discuss and develop ideas with. I don't see why it is sometimes challenging to work closely with local staffs who are seemingly less qualified and feel shy to come forward for a sound discussion benefitting our students. I have previously shared ideas a few times over with the academic director on this campus, but no action was taken..."

The above quote from another Business Lecturer from the selected college in north-east China shows a different scenario where they are little or no communication between local and non-local staff, but more importantly the fact that they teach similar subject areas of their expertise. From the learners' viewpoint, however, it is a loss in terms of new input being delivered as opposed to repeat content. The content shared in a second-year course is delivered again during a similar course in third year.

"The assignment is very similar to what we did last year, however the instructor is different. The content is the same but it's easier to follow this year because the instructor is Chinese and she speaks in Chinese as when needed. Though the content was the same last year, it was difficult to follow the foreigner teachers' accent and vocabulary as our English levels were not that high"

"...the learning outcomes on the ppt are different to questions in quiz and group presentations... we don't think the teacher always know what the course level expectations are for us..."

These two above quotes are from a third year International Business student and a second year Marketing student who shares his view on repeat content delivered over two years on similarly named courses, but also how benefits from a Chinese teaching delivery. A peer-review or teaching content monitoring could potentially address issues such as the above.

\subsection{Lack of Multi-Cultural Learning Ecosystem in Staff Rooms}

"Foreign teachers live their expat life and mostly spent their time on their own, we don't communicate much on a daily basis unless we are contacted for any support. It is great to have them for our students but we don't need many communications... Language and culture barrier is a problem when talking at a length... My line manager is the Dean who I also serve as an assistant with occasional visits to our other campuses in China..."

The above quote from a Chinese staff at one of the colleges where she teaches English to first year students. While she expresses understandable reasons for lack of regular communication with non-Chinese staff, the college is designed to be multi-cultural and the culture is aimed at inclusivity and participation of different cultures.

"When I first came, I was told that $X$ would be my contact person and also someone I could contact if I needed any support setting myself up in this foreign land... I didn't however reach out much to her as I can arrange things for myself and it's not hard...everything is available within a mile's distance... a semester later, she was allocated to me as my teaching assistant and I don't know where her office room is or what her subject areas are... it would be beneficial for the college if local and nonlocal staff could work together more closely..."

A non-Chinese Lecturer expresses his interest in collaborating with local Chinese staff members. While culture is a strong element in this aspect, it remains much with the higher education institution to foster and emphasise a particular culture to facilitate such collaboration of local and non-local staff for a wider inclusive experience for everyone involved.

"When I joined the college, the Dean (Chinese) confirmed that share of marking exams for large courses and student cohorts will be split in half between me and my teaching assistant (Chinese), however shortly after an assessment was due for one of my $2^{\text {nd }}$ and $4^{\text {th }}$ year courses I had to mark around 650 papers all by myself... the turnaround time was about a week... so there was no sensible way to provide a good quality feedback to the students, simply due to sheer scale of marking....The Dean and also the teaching assistant didn't respond to their earlier statement of confirmation when asked... There was no one else to report this to... I had asked details of the vice-president of the college who sits directly above the Dean but he was not contactable... it's in a way explains why the attrition rate is so high here..." 
A foreigner Business Lecturer reports this from his experience in working with one of the selected colleges in Jilin province. Given the low staff morale and lack of clarity provided in job description, the attrition rate has been historically high in the college. As with the college in Sichuan province, this college mentioned above don't provide staff details online or have any HR policy.

\subsection{Missed Learning Objectives and Teacher-Student Office Hours}

"I am building on the course resources provided to me in the teaching portfolio from previous years. I did not teach microeconomics last year; the previous teacher left these resources for me. From my experiences, the course outlines are set by the partner institutions that are running the courses on their campus in parallel to ours. There is, however, much space and flexibility in delivering our courses delivered here... There is no standardisation mechanism in place, in both delivery and assignment design aspects... This allows teachers to focus on aspects they think is important in a Chinese classroom and remove sections from the curriculum that cannot be covered... Duration of the semester and student capacity are two key important factors to keep in mind when you teach in China."

Following what this Economics Lecturer, working for this college in Sichuan province, has to say here demonstrates the degree of flexibility in course design and delivery while at the same time illustrates the wide gap or even lack of monitoring or quality assurance mechanism in place. Since there are no staff meetings or regular line manager meetings in place, which happens to be a likeable element amongst the staffs working in the college, there is also zero quality assurance in the courses delivered to colleges. Universities that go through accreditation reviews would at the very least pinpoint at the importance of achieving the learning objectives as defined and shared in the course outlines. However, how much of that is equally delivered by partner colleges abroad also needs significant effort, attention and time.

While most Chinese students are not encouraged to actively participate in classroom from their early years, the same is continued in their years in higher education unless a different class culture is introduced and reinforced through continuity. It is apparent from the teaching pedagogy from the foreign (non-Chinese) lecturers that they try different ways to involve the Chinese students in the classroom, many have struggled to make this happen with little or no support from the college in general. In the context of assignments and its design, an area where a lot of students come forward for clarification, the workload given in office hours is almost negligible. Only 6 of the total interviewed staff members offers a monthly one to two hours of office hours to students, particularly if this is about assignment clarification outside classroom hours and also feedback based language learning sessions. For subject Lecturers, there is almost no provision of office hours where students could connect with their class Tutors outside classroom hours. This leads to significant distress and helplessness amongst students who often complain weighing the amount of fees and support received in exchange.

\subsection{Varying Financial and Moral Incentives}

Due to the fact that some staff members are either paid in cash or via e-transfer on WeChat, detailed evidence of role-based payments are missing, however interviews suggested that the pay structure is pretty dispersed and uneven. While some foreign staffs are paid according to their highest qualification and other attributes, others (mainly locals) are paid as per agreement and seniority at the institution (not in the sector, in general). On recruitment site, there is a range provided for subject level lecturers, however for local recruits the pay structure varies significantly. In addition, the mismatch of qualification and teaching areas are vastly overlooked which significantly affects the learning objectives of courses that a large cohort of students take as a part of their degree programme. The lack of monitoring in this scenario doesn't benefit or stabilize the pay gap. One of the three colleges studied, with partners in North America and the US did not have an allocated HR division where any such related information could be further researched. They have Finance and International offices as a part of their outreach division, responsible for staff recruitment, pay, administration and student registration/fee management. The lack of HR and paperwork makes it very difficult to monitor and identify these discrepancies. Most staff members working in these international offices and HR divisions in the three colleges, are local and support the guanxi induced job security model discussed earlier in the literature, leading to their long-term employment with their respective employers.

"I applied directly from my job site and was interviewed in line with the competencies set out for the role... I shared my teaching and research interests and also had enquired of support available for conferences and paper submissions... The Dean responded positively to the questions, however after I had started working here then I realised the job is mainly teaching based and no workload hours or pay for research activities are encouraged or available... My qualifications are much higher than my junior Chinese colleagues but their job description and pay is almost the same... This explains why I was unable to read staff profiles online before I arrived... and Chinese staff stay close to the management, we don't get to talk to know much about them..." 
Comments from a foreigner staff member when asked about how he got his job and experiences from her first few months on the new campus.

"My experience with the college has mostly been good... I was a student here myself six years ago and then had went abroad for my Master's degree, when I came back my family connection at the department and local council helped me quickly secure this job without wasting much time on job hunting in a highly competitive modern China... I get to work closely with the Dean and though I support foreign teachers with their teaching, my job is mainly administrative and operational... My goal is to work here for a few more years since I live with my family close to campus and don't want to move to another company without knowing anybody or referrals"

This guanxi based recruitment offered the candidate the same position and compensation package when appointed, as the college did to a senior foreigner staff with much higher qualification and HE experience abroad.

Table 3: Identification of Themes

\begin{tabular}{|l|l|l|}
\hline First order codes & Second order codes & Themes \\
\hline $\begin{array}{l}\text { Undefined staff qualification and } \\
\text { misleading entry point conditions }\end{array}$ & $\begin{array}{l}\text { Lack of clarity in roles and faculty } \\
\text { requirements during and post - } \\
\text { appointment stages }\end{array}$ & $\begin{array}{l}\text { Mismatch between profile and } \\
\text { output - affecting learning outcomes }\end{array}$ \\
\hline $\begin{array}{l}\text { Separated staff circles within similar } \\
\text { subject group interests }\end{array}$ & $\begin{array}{l}\text { Missed opportunity on team work } \\
\text { and staff meetings }\end{array}$ & Best practices (not) shared \\
\hline $\begin{array}{l}\text { Chinese and non-Chinese staff } \\
\text { dynamics }\end{array}$ & $\begin{array}{l}\text { Need based communication, much } \\
\text { collegiality missing though mentioned } \\
\text { at college goal and mission } \\
\text { statements }\end{array}$ & $\begin{array}{l}\text { Need to foster a multi-cultural } \\
\text { learning ecosystem in staff room }\end{array}$ \\
\hline $\begin{array}{l}\text { Missed learning objectives and } \\
\text { teacher-student office hours }\end{array}$ & $\begin{array}{l}\text { A mix of formative assessment details } \\
\text { and preparation all in limited class } \\
\text { hours, lack of feedback in detail }\end{array}$ & $\begin{array}{l}\text { Course learning objectives need } \\
\text { revisiting (before release of final } \\
\text { grades) }\end{array}$ \\
\hline $\begin{array}{l}\text { Mismatch of curriculum content and } \\
\text { staff delivery }\end{array}$ & $\begin{array}{l}\text { Peer-monitoring and teaching } \\
\text { reviews could benefit both staff and } \\
\text { learners }\end{array}$ & $\begin{array}{l}\text { Lack of monitoring and quality } \\
\text { assurance practices }\end{array}$ \\
\hline Varied incentives and pay packages & $\begin{array}{l}\text { Missing information from HR and } \\
\text { details of pay entitlements could lead } \\
\text { to scrutiny and questionable } \\
\text { reputation of college }\end{array}$ & $\begin{array}{l}\text { Need for foreign university partners } \\
\text { to formalise the processes and get } \\
\text { involved in the recruitment loop to } \\
\text { avoid corruption }\end{array}$ \\
\hline
\end{tabular}

\section{DISCUSSION}

\subsection{Improving Transparency and Collegiality for Sharing 'Best Practices'}

The findings evidences that there is a clear discrepancy in regards to staff qualifications and pay packages when they are compared between Chinese and non-Chinese staff members recruited at the selected colleges studied, and there are deeper implications of these in the long run that can be further discussed and debated. One of the foremost considerations made by the incoming students of these colleges are based on their gao kao (high school, A-level equivalent in China) results are significantly lower than students who would go on to leading and other central Universities in China. The entry requirements for the selected colleges looked at are much lower, however the college fees are almost as high as a foreign university would take in some countries. The typical range of student fees paid to these foreign University-partnered colleges are between 45000-65000 RMB every year, which is substantially higher than what students would pay in a Chinese University. Despite the high fees, the students most often do not get to find out details of their courses and subjects offered during an academic year until the very last minute, this can be two-three days before the semester commences.

As evident from what the data suggests, the staff recruited for teaching subject level and English language courses have significant variation in their qualification, background experience and teaching pedagogy. In addition to these, the dynamics between Chinese and non-Chinese staffs are not found at a level where it would be expected at a foreign University-partnered college environment. Besides the lack of monitoring mechanism and also empirical ignorance of fostering the culture to embed local, non-local staff collaborative learning environment, the student misses out significantly in regards to their overall learning outcomes and course expectations. Teachers without the required right qualifications, reading out from PowerPoint provided either by the publisher or previous year portfolio base are not able to deliver a systematic, participatory and industry-tailored high-quality course. However, some of the staff who are at the right level are found to be neither 
encouraged nor supported to deliver a high-quality lesson with all necessary recognition and more importantly, sharing the best practise with other staffs on campus.

\subsection{Aligning Staff Recruitment, Quality Assurance and Teaching Evaluation Needs}

Since there is only 8 staffs whose profile are visible online with limited information (qualifications, current role and contact details), it is almost difficult to monitor or compare staff recruitment standards, or to see course allocation of individual staff matching their experience and background. It can be observed from the data that lack of monitoring of teaching via peer review of staff meeting practices adversely affects the delivery and quality of teaching in the classroom. While rising student dissatisfaction is an issue, interviews with learners also shows that compliance with the school practices is something that is also a reality amongst students. This allows regular continuation of the same practice year after year on the college campus without any changes. It is however interesting to see how several staff sometimes share the same class cohort while teaching on different modules, a very common reality in Universities, but have no contact with each other. This can be attributed to several causes as understood from the findings a) local and non-local staff do not communicate due to personal fears, dissimilar qualifications (even when teaching at the same level), culture and language barrier, b) the absence of regular (or at least once a term) school meetings and also the lack of a shared staff room, c) the access challenge of reading the course outlines online or when documentation is requested from teaching assistants (mainly guanxi recruited) which would facilitate one staff from another after understanding what content is reviewed and shared with the same learners, d) inability and lack of interest amongst students to go and report to the management to express their dissatisfaction in qualitative differences in lessons.

"We had struggled with over-assessment for an academic skills course last year, and being the student monitor I reported against a particular teacher to the management... no action was taken, no changes were made and the following year we were given the same teacher again... we cannot see eye to eye after that..."

A final (fourth) year international business student shares from this experience in the college. Deviation from the course learning objectives, as discussed earlier in the paper stands as a major challenge as that is something would require monitoring from the partner University abroad. Due to the fact that no such QAA (Quality Assurance Agency for higher education) format reviews are carried out annually, and such inspection is expected from internal management of the college - no revalidation or quality control board/staff meeting takes place. As can be noted above, the quality assurance is another one of the many roles that the Academic Dean is entrusted with but no such reports are available.

"Our teachers have a lot of autonomy with their courses. We do not interfere in the process and provide a lot of admin support as required. When students or their parents complain, we remind them that finishing assignments is their responsibility... We have to maintain the standard set by our partner US school... We do not compromise on that"

The above quote from the Academic Dean from one of the colleges in Jilin province does not cover the grey area of teaching quality assurance and also admin support. The staff from this same college had reported regarding the discrepancy in marking allocation for large student cohorts and lack of moderation or standardisation process. In the overall understanding of this and the clear lack of quality maintenance, it is imperative that the foreign partner University need to exercise some level of control when it comes to course and teaching quality and not simply settle with annual student-intake and financial agreements as it so happens.

\subsection{The Degree of Involvement and Association by Foreign Partner Institutions}

Following from the previous case in point, the need for foreign partner Universities are paramount and imperative from the findings of the research. While there is an increasing evidence of pressure coming in to these colleges in China from their partner institutions abroad in regards to students who would finish one length of their degree abroad after spending the first 2-3 years in China, little is being done in terms of quality control and staff recruitment. Guanxi based staffs in the colleges do not have an online profile and very often paid in an envelope every month, so a transparent record of transactions, staff numbers, and role-based pay information are all largely missing in paper. Earlier evidence shows that guanxi based teachers are also delivering courses at second- and third-year levels without their right subject background or the right qualification which would otherwise be held mandatory for other/ non-guanxi/ foreign/ other Chinese staff members. There is some evidence from other foreign partner institutions who have branches on china campus, where all the recruitment is done centrally from US or Canada main office. These hired staffs are then allocated to their foreign campuses. Whether or not these processes have favouritism embedded in them, may well be a subject topic for another research, but the control in terms of ensuring consistent pattern of staff hiring based on the right criterion is present. 


\section{CONCLUSION AND IMPLICATIONS}

Further research could address the candidate homogeneity aspect of this research in terms of studying staff at a particular position level (i.e. Lecturer grade A and B) used for data and analytical consistency benefitting this research. Larger data sets across positions and local/ non-local staffs may generate more themes with varied implications. Additionally, studying more such colleges across the mainland territory, similar in scale and operations, would bring in different or similar conclusions. Also, research in other sectors where guanxi is still a criterion of recruitment, that involves triple helix connection could be looked at with higher focus on organisational goals and teaching quality. Finally, similar studies can be conducted in western societies where potentially similar results could be found. A similarity in responses between the two may suggest one of two things: that guanxi has become more of a non-unique sense of social networking and social capital, howsoever defined and perceived culturally.

This research is based on the findings from three comparable foreign University-partnered colleges in China where the senior management is solely composed of Chinese nationals. It shows that there are several areas of discrepancy and lack of transparency when staffs are hired and paid on guanxi basis; challenges coming from guanxi-based staff not working closely with non-guanxi counterparts (even when they are teaching on the same course), the lack of access of staff profiles and inability of non-guanxi staff to communicate with guanxi-based staffs. The effects on the wider scale falls on student learning, image of foreign Universities, very high staff attrition rate, quality control measures and falling reputation of these colleges nationally within mainland China.

The importance of achieving the learning outcomes, high quality teaching and student support, being recognised for student excellence and also graduate recruitment are essential components defining the very foundation and basic success factors of a higher education sector that faces a stiff competition globally. Throughout the past decade in particular, the Chinese higher education sector has opened up to the wider world more than ever before and successful claims in academic research and excellence in teaching offered in mainland colleges and Universities have been loudly marketed. However, the challenges and realities from the inner worlds of sino-foreign colleges, as presented in the paper shows that they could be vulnerable to significant challenges when thoroughly scrutinised under strict academic governance. It is also worth noting that several SinoBritish partnership colleges as well as US/ Canada/ Australia/ New Zealand HE institution-partnered colleges are exponentially growing in China and staff recruitment, with reduced dependency on guanxi, is a key area of quality control for world-class teaching delivery as their advertisements usually tend to claim. There is also increasing number of British and Australian Universities who have Chinese campuses and there may be quite a handful to learn when it comes to how recruitment is managed in terms of a) transparency of application procedure for potential faculties b) clear guideline of application and required/essential/desired selection criterion c) suitably providing an online profile of staff members, d) clear and easy access to study portfolio and course handbooks online available for both students and staffs, f) a dedicated HR team organising the basics of benefits and compensation packages. Additionally, colleges can internally manage student evaluation surveys that are actually actionable and not simply for records sake. On a concluding observation, as higher education institutions in China start building on their expansion (operational as well as ambitious student-intake goals) plans coupled with foreign-University partnerships, they would find that potential labour-pool (and the degree and extent of expertise that comes with it) drawn solely through relationship networks will be miniscule and risky, also perhaps too local and interconnected to be able to fulfil any acceptable level and quality of function.

\section{REFERENCES}

Abosag, I., \&Naudé, P. (2014). Development of special forms of B2B relationships: Examining the role of interpersonal liking in developing Guanxi and Et-Moone relationships. Industrial Marketing Management, 43 (6): 887-896

Alston, J.P (1989). Wa, guanxi, and inhwa: Managerial principles in Japan, China and Korea. Business Horizons. 32(2): 26-31

Ambler, T. Styles, C., \& Xiucun, W. (1999). The effect of channel relationships and guanxi on the performance of inter-province export ventures in the. People's Republic of China. International Journal of Research in Marketing, 16(1): 75-87

Braun, V. \& Clarke, V. (2006). Using thematic analysis in psychology. Qualitative Research in Psychology, 3 (2): 77-101.

Boyatzis R. (1998). Transforming Qualitative Information: Thematic and Code Development. Thousand Oaks, CA: Sage Publications; 1998

Cai, S., Jun, M., \& Yang, X. (2010). Implementing supply chain information integration in China: The role of institutional forces and trust. Journal of Operations Management, 28(3): 257-268

Chen, Y., Friedman, R., Yu, E., \& Sun, F. (2011). Examining the Positive and Negative Effects of Guanxi Practices. SSRN Electronic Journal, (28): 715- 735. 
Cheung, M., Wu, W., \& Wong, M. (2013). Supervisor-subordinate kankei, job satisfaction and work outcomes in Japanese firms. International Journal of Cross-Cultural Management, 13(3): 265-278

Crabtree. B., Miller, W. (1999). Doing Qualitative Research. 2. Newbury Park, CA: Sage Publications

Dana, L. P., \& Dana, T. E. (2005). Expanding the scope of methodologies used in entrepreneurship research. International Journal of Entrepreneurship \& Small Business, 2(1): 79-88.

Dana, L. P., \& Dumez, H. (2015). Qualitative research revisited: epistemology of a comprehensive approach. International Journal of Entrepreneurship and Small Business, 26(2): 154-170.

Davies, H., Leung, T.K., Luk, S.T., \& Wong, Y.H. (1995). The benefits of 'Guanxi': The value of relationships in developing the Chinese market. Industrial Marketing Management, 24 (3): 207-214.

Daly, J., Kellehear, A. \& Gliksman, M. (1997). The Public Health Researcher: A Methodological Approach. Australia: Oxford University Press. Dunning, John H. and Changsu Kim. "The Cultural Roots of Guanxi: An Exploratory Study." The World Economy. Vol 30 no. 2. Oxford, 2007 Eisenhardt, K.M. (1989). Building Theories from Case Study Research The Academy of Management Review; 14 (4)

Fock, H. K. Y., \& Shing, W. (2003). The China Market: strategic implications of guanxi. Business Strategy Review 9(3): 33-43

Gu, Flora F., Hung, Kineta H., Tse, David K. (2008). When Does Guanxi Matter? Issues of capitalization and its dark sides. Journal of Marketing 72(4):12-28

ICAC (1993), Hong Kong investors rely on guanxi to do business in China. Oriental Daily News

Nguyen, B., Simkin, L., \& Canhoto, A. (2015).The dark side of CRM. London: Routledge.

Rice, P., \& Ezzy, D. (1999). Qualitative research methods: A health focus. Melbourne: Oxford University Press.

Simmons, L.C. and Munch, J. (1996). Is relationship marketing culturally bound: a look at guanxi in China. Advances in Consumer Research 23: 92-96

Scott, J., Harrison, R., Hussain, J., \&Millman, C. (2014). The role of Guanxi networks in the performance of women-led firms in China. Internatinal Journal of Gender And Entrepreneurship, 6(1): 68-82.

Tsang, E. (1998). Can guanxi be a source of sustained competitive advantage for doing business in China? The Academy of Management. Executive, 12 (2): 64-73

Wong, Y., Wong, S., \& Wong, Y. (2010).A study of subordinate-supervisor Guanxi in Chinese joint ventures. The International Journal Of Human Resource Management, 21(12): 2142-2155.

Yang, M. M. H. (1994). Gifts, favors and banquets: The art of social relationships in China. Cornell, NY: Cornell University Press

Zhai, Q., Lindorff, M., Copper, B. (2013). Workplace Guanxi: Its dispositional antecedents and mediating role in the affectivity-job satisfaction relationship. Journal of Business Ethics 117: 541-551 